\title{
PROPOSTA DE IMPLANTAÇÃO DO PLANEJAMENTO E CONTROLE DA MANUTENÇÃO (PCM) EM UM SISTEMA DE REFRIGERAÇÃO NA UNIVERSIDADE FEDERAL DO CEARÁ
}

Rayane Araújo Lima (Universidade Federal do Ceará) rayanearaujo@alu.ufc.br Carla Amanda Matos Lima (Universidade Federal do Ceará) amandamtsl@alu.ufc.br

Hévilla Souza Oliveira (Universidade Federal do Ceará) hevillasouza@alu.ufc.br Daiane de Oliveira Costa (Universidade Federal do Ceará) daianecosta@ufc.br Vicente Mateus da Silva Paz (Universidade Federal do Ceará) vicentemateus21@ gmail.com

\section{Resumo}

Com o passar dos anos o mercado transformou-se em um ambiente altamente competitivo. Este fato ocasionou o acirramento entre empresas do mesmo ramo em busca de suprir as necessidades dos clientes e ganhar espaço. Assim, a implantação e efetividade das atividades de manutenção tornaram-se um dos fatores fundamentais para o alcance da redução de desperdícios nas organizações e aumento dos seus lucros, possibilitando o destaque destas frente aos seus concorrentes. O presente estudo possui como objetivo a elaboração de um modelo de Planejamento e Controle da Manutenção para os equipamentos de ar-condicionado da UFC - Campus Russas, visando uma maior eficiência do sistema de refrigeração da instituição. O procedimento aplicado caracteriza-se como estudo de caso de abordagem qualitativa. Para a adequação das metodologias do PCM à instituição, foi realizado um modelo de tagueamento para os aparelhos de ar-condicionado, padronizou-se as ordens de serviço e o cadastro dos diferentes modelos de aparelhos, bem como sua análise de criticidade. Também foi proposto a elaboração de um histórico de falhas e manutenções efetuadas, a capacitação de mantenedores, além de um plano de manutenção preventiva e o uso de indicadores. Diante do estudo, percebeu-se a importância do PCM para a instituição, visto que ele permitirá um maior controle sobre a vida útil dos equipamentos, redução do número de defeitos e quebras, uma maior restrição dos custos com paradas e manutenções, além de garantir mais conforto para os alunos e servidores da instituição.

Palavras-Chaves: PCM. Análise de criticidade. Plano de Manutenção. 


\section{Introdução}

Com o passar dos anos o mercado transformou-se em um ambiente altamente competitivo. Este fato ocasionou o acirramento entre empresas do mesmo ramo em busca de suprir as necessidades dos seus clientes e ganhar espaço. Assim, os serviços de manutenção tornam-se imprescindíveis, uma vez que proporcionam uma maior redução dos desperdícios, diminuição da taxa de falhas do processo, bem como do tempo de produção e entrega, fornecendo à organização meios para se sobressair frente aos concorrentes.

Para isso, é importante o uso de metodologias que busquem a melhoria contínua dos processos de forma a realizar o gerenciamento dos recursos disponíveis, definindo estratégias para aumentar o desempenho do sistema.

O Planejamento e Controle da Manutenção (PCM) tem como objetivo assegurar confiabilidade dos insumos do processo produtivo de forma a elevar a disponibilidade dos ativos, maximizando a produtividade da organização. Esta atividade de gestão da manutenção se dá por meio de ações estratégicas que gerenciam os serviços de manutenção de modo a direcionar as ações aos propósitos que atendem às necessidades do negócio (SOUZA, 2008).

O Diário Comércio Indústria \& Serviços (2018) afirma que embora a crise econômica tenha afetado os fabricantes de ar-condicionado, em 2017 houve um progresso nas vendas dos aparelhos "splits" em 24\%, o que representa uma recuperação moderada deste setor, estabelecendo uma expectativa de crescimento para os anos posteriores. Este fato ocorre devido à sensação de conforto e bem-estar que ambientes climatizados proporcionam, impactando no rendimento e eficiência dos locais de trabalho, justificando a importância do uso destes aparelhos.

Logo, o presente estudo possui como objetivo a elaboração de uma proposta para implantação do PCM para os equipamentos de ar-condicionado da UFC - Campus Russas, visando um aumento na eficiência do sistema de refrigeração da instituição. O propósito é assegurar que as práticas de manutenções ocorram no momento adequado, reduzindo o índice de quebra dos equipamentos e aumentando a sua vida útil, além de garantir mais conforto para os alunos e servidores da instituição. 


\section{Referencial teórico}

\subsection{A importância da manutenção}

A manutenção consiste, de acordo com a NBR 5462, na "combinação de todas as ações técnicas e administrativas, incluindo as de supervisão, destinadas a manter ou recolocar um item em um estado no qual possa desempenhar uma função requerida" (ASSOCIAÇÃO BRASILEIRA DE NORMAS TÉCNICAS, 1994, p. 6).

Nos últimos anos a manutenção tem deixado de ser uma atividade de reparo voltada à correção de defeitos de máquinas e equipamentos, tornando-se uma estratégia presente no processo produtivo e que proporciona à organização o alcance de seus resultados.

Frente a isto, Viana (2002, p. 5) assegura que "a manutenção não pode se limitar a apenas corrigir problemas cotidianos, mas deve perseguir sempre a melhoria constante", assim, a qualidade dos produtos é alcançada através do aperfeiçoamento dos processos, eliminando ao máximo os defeitos provenientes das falhas dos equipamentos e garantindo segurança e maior lucratividade. Um dos meios para o alcance desses objetivos consiste na aplicação de conceitos do Planejamento e Controle da Manutenção (PCM).

\subsection{PCM}

Carvalho et al. (2009) definem o PCM como um conjunto de ações com a finalidade de preparar, programar e verificar os resultados obtidos com as atividades de manutenção e assegurar a correção dos desvios para que as metas da empresa sejam alcançadas.

O setor de PCM, de acordo com Carvalho et al. (2009), possui como atribuições o controle de informações e avaliação de resultados para o auxílio na tomada de decisão dos gerentes de Produção, Operação e Manutenção. Portanto, Carvalho et al. (2009) e Viana (2002) indicam que o PCM é um órgão de staff, capaz de fornecer o suporte necessário às operações de manutenção e assim possuir proximidade direta com todos os departamentos de produção.

O modelo de prática empresarial adotada pelo PCM direciona todas as atividades das organizações a uma busca por processos continuamente melhores que estejam interrelacionados aos objetivos estratégicos da empresa.

Dado que a organização das atividades de manutenção é uma tarefa complexa, Viana (2002) define quatro etapas fundamentais (Figura 1) a serem realizadas no PCM. 
Figura 1 - Etapas do PCM

\begin{tabular}{|c|}
\hline Etapas do PCM \\
\hline Organização da manutenção; \\
\hline Cadastros necessários ao PCM; \\
\hline Planos de Manutenção; \\
\hline Planejamento e Controle da Manutenção; \\
\hline
\end{tabular}

Fonte: Adaptado de Viana (2002)

\subsubsection{Organização da manutenção}

\subsubsection{Tagueamento}

O primeiro passo do PCM é o tagueamento, que se enquadra na etapa de organização da manutenção. Segundo Hünemeyer (2017), o termo tagueamento em manutenção é utilizado para etiquetar os ativos de uma empresa e classificá-los segundo níveis hierárquicos. Carvalho et al. (2009) garantem que a utilização desta técnica possibilita localizar o equipamento em áreas operacionais, pois se torna cada vez mais necessário o controle setorizado das áreas de produção e a maior organização da manutenção.

Este deve seguir características estabelecidas por padrões de codificação, como mostra a Figura 2:

Figura 2 - Características do tagueamento

\begin{tabular}{|c|}
\hline Características do tagueamento \\
\hline Unicidade: garante um código diferente para cada item; \\
\hline Simplicidade: uso de poucos caracteres; \\
\hline Formato padronizado, estruturado em um padrão lógico; \\
\hline Classificável: para agrupar materiais e máquinas com características semelhantes; \\
\hline Expansivo: planejado para suportar o crescimento da empresa; \\
\hline Operacional: para oferecer praticidade e robustez no uso; \\
\hline Versátil: aplicações variadas; \\
\hline
\end{tabular}

Fonte: Adaptado de Gasnier et al. (2007) apud Hünemeyer (2017)

Viana (2002) e Carvalho et al. (2009) citam que é possível ocorrer uma extração de informações mais fácil de uma determinada Tag (número de quebra, disponibilidade do equipamento, obsolência, etc.), quando ocorre um tagueamento bem especificado e organizado. 


\subsubsection{Ordem de serviço}

Após a elaboração do tagueamento, Viana (2002) aponta que é necessária a escolha do fluxo do serviço de manutenção e a classificação das Ordens de Serviço (OS) que chegam ao PCM de acordo com seu impacto na produção. Também classificada dentro da etapa de organização da manutenção, a OS pode ser definida em quatro modalidades, conforme a Figura 3:

Figura 3 - Modalidade de uma OS

\begin{tabular}{|c|}
\hline Modalidades de uma Ordem de Serviço \\
\hline Solicitação de Serviço (SS) aberta pela operação de algum equipamento; \\
\hline Ordem de Manutenção (OM) estabelecidas por meio dos planos de manutenção; \\
\hline Ordem aberta pelo executante por meio de emergências; \\
\hline Ordem via inspeção no campo; \\
\hline
\end{tabular}

Fonte: Adaptado de Viana (2002)

Carvalho et al. (2009) expressa que a OS possui um ciclo de vida, composto pelas fases: não iniciada, programada, iniciada, suspensa e encerrada. Tudo referente a esta autorização de trabalho deve ser registrado para que a tomada de decisão do programador da manutenção seja simplificada e um histórico referente ao funcionamento do equipamento seja elaborado.

\subsubsection{Cadastros necessários}

\subsubsection{Análise de criticidade}

Considerada como a segunda fase do PCM, onde se realizam todos os cadastros necessários logo após o reconhecimento dos componentes existentes. É um input importante para embasar a tomada de decisão durante a gestão de risco dos ativos, pois é onde ocorre a priorização dos equipamentos para posterior execução de ações planejadas.

De acordo com Costa (2013), é necessário um estudo de cada área e ativos físicos existentes frisando na análise de criticidade, uma vez que sem este detalhamento é improvável conseguir estabelecer um plano de manutenção que forneça uma redução dos custos e aumento da disponibilidade e vida útil dos equipamentos.

Os ativos devem ser diferenciados em críticos e não críticos mediante aspectos como interferência na parada de produção, perda de faturamento, perda de qualidade, dentre outros, para desta forma analisar o impacto de sua indisponibilidade a partir da designação do tempo em que ele poderá ficar inoperante devido a uma parada inesperada (HÜNEMEYER, 2017). 
Existem metodologias que auxiliam na classificação dos ativos, como o método $\mathrm{ABC}$, mostrado por Dynamox (2019), onde se utiliza um sistema de classificação baseado na gravidade da ocorrência das falhas mediante níveis pré-definidos de impacto, determinando o nível de criticidade dos equipamentos, bem como o tipo de manutenção a ser realizado por meio de um fluxograma decisional (Figura 4). Assim, as máquinas serão classificadas mediante os seguintes níveis:

- A: equipamentos com alta criticidade;

- B: equipamentos que possuem criticidade moderada;

- C: equipamentos com baixa criticidade.

Figura 4 - Fluxograma decisional para definição do nível de criticidade

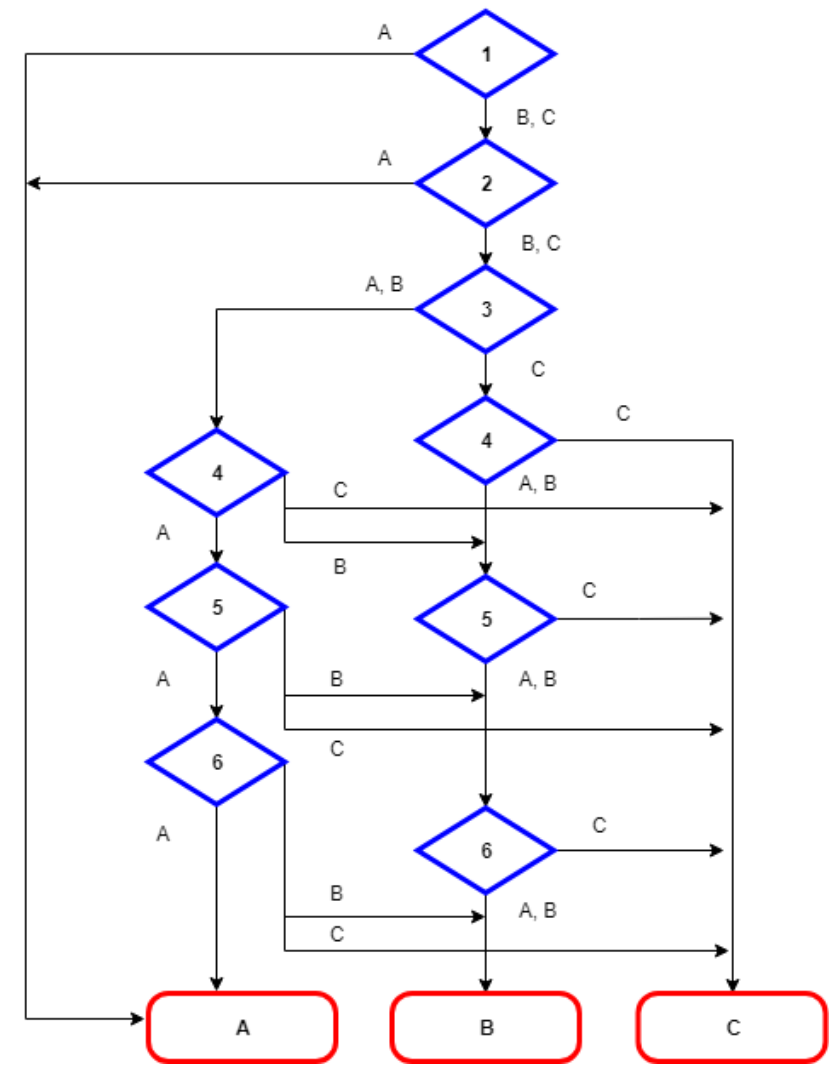

Fonte: Dynamox (2019)

\subsubsection{Planos de manutenção}

Segundo Viana (2002), os planos de manutenção consistem em um planejamento do conjunto de atividades e informações necessárias para direcionar a manutenção preventiva. Algumas informações fundamentais para a elaboração das ordens de manutenção são definidas no Quadro 1. 
Quadro 1 - Informações importantes para elaboração da ordem de manutenção

\begin{tabular}{|c|c|}
\hline \multicolumn{2}{|c|}{ ORDEM DE MANUTENÇÃO } \\
\hline Título do plano de manutenção & $\begin{array}{l}\text { Importante para relacionar o plano com a tag } \\
\text { do equipamento }\end{array}$ \\
\hline Grupo de máquina & $\begin{array}{l}\text { Refere-se a família na qual o plano irá ser } \\
\text { efetuado }\end{array}$ \\
\hline Periodicidade & $\begin{array}{l}\text { Intervalo de tempo em que será criada uma } \\
\text { ordem de manutenção }\end{array}$ \\
\hline Tipo de dia & $\begin{array}{l}\text { Determinação se será realizada em dias úteis } \\
\text { ou corridos }\end{array}$ \\
\hline Data da ativação & $\begin{array}{l}\text { Marco inicial da execução do plano de } \\
\text { manutenção }\end{array}$ \\
\hline Equipe de manutenção & $\begin{array}{l}\text { Refere-se aos responsáveis por efetuar as } \\
\text { atividades relacionadas a manutenção }\end{array}$ \\
\hline Planejador & Responsável pela criação do plano \\
\hline Material de consumo & $\begin{array}{l}\text { Insumos necessários para realizar as } \\
\text { atividades da ordem }\end{array}$ \\
\hline Especialidades & $\begin{array}{l}\text { Delegação dos mantenedores que irão fazer } \\
\text { as tarefas }\end{array}$ \\
\hline EPI's & $\begin{array}{l}\text { Equipamentos de proteção individual que os } \\
\text { colaboradores obrigatoriamente devem usar }\end{array}$ \\
\hline Ferramentas & $\begin{array}{l}\text { Instrumentos indispensáveis para a } \\
\text { manutenção }\end{array}$ \\
\hline Equipamentos de apoio & $\begin{array}{l}\text { Maquinário auxiliares para a efetividade da } \\
\text { manutenção }\end{array}$ \\
\hline
\end{tabular}

Fonte: Adaptado de Viana (2002)

\subsubsection{Manutenção produtiva total}

Na terceira fase do PCM encontra-se a Manutenção Produtiva Total (TPM) que, para Singh et al. (2013), trata-se de uma abordagem inovadora à manutenção que otimiza a eficácia do equipamento, elimina falhas e promove a manutenção autônoma do operador nas atividades diárias, assim, objetiva melhorar a produtividade e a qualidade, juntamente com o aumento da moral dos funcionários e satisfação no trabalho.

Segundo Kigsirisin et al. (2016), Nagajima, um dos principais colaboradores da TPM, indica que para atingir seu objetivo, a implementação dessa política deve ser feita através da estratégia dos oito pilares, cuja descrição é sintetizada por Kardec e Nascif (2009), conforme o Quadro 2. 
Quadro 2 - Pilares da TPM

\begin{tabular}{|l|l|}
\hline \multicolumn{1}{|c|}{ PILAR } & \multicolumn{1}{c|}{ OBJETIVo } \\
\hline Melhoria focada & $\begin{array}{l}\text { É focar na melhoria global do negócio. Desse } \\
\text { modo, procura-se reduzir os problemas para } \\
\text { melhorar o desempenho. }\end{array}$ \\
\hline Manutenção autônoma & $\begin{array}{l}\text { Autogerenciamento e controle, liberdade de } \\
\text { ação, elaboração e cumprimento de padrões, } \\
\text { conscientização da filosofia TPM. }\end{array}$ \\
\hline Manutenção planejada & $\begin{array}{l}\text { Significa ter realmente o planejamento e } \\
\text { controle da manutenção. }\end{array}$ \\
\hline Educação e treinamento & $\begin{array}{l}\text { Ampliação da capacitação técnica, gerencial, } \\
\text { comportamental do pessoal de manutenção e } \\
\text { operação. }\end{array}$ \\
\hline Controle inicial & $\begin{array}{l}\text { Estabelecimento de um sistema de } \\
\text { gerenciamento. }\end{array}$ \\
\hline Manutenção da qualidade & $\begin{array}{l}\text { Estabelecimento de um programa de zero } \\
\text { defeito. }\end{array}$ \\
\hline TPM office & $\begin{array}{l}\text { Estabelecimento de um programa de TPM } \\
\text { nas áreas administrativas, visando o aumento } \\
\text { de sua eficiência. }\end{array}$ \\
\hline Segurança ou SHE & $\begin{array}{l}\text { Estabelecimento de um sistema de saúde, } \\
\text { segurança e meio ambiente. }\end{array}$ \\
\hline
\end{tabular}

Fonte: Adaptado de Kardec e Nascif (2009)

\subsubsection{Manutenção autônoma}

A Manutenção Autônoma consiste em um dos pilares da TPM e possui o intuito de prover altos níveis de produtividade no ambiente de trabalho por intermédio de atividades realizadas pelos próprios operadores. Ela "permite detectar e tratar pequenas anomalias antes que elas se desenvolvam e conduzam a falha do equipamento" (FOGLIATTO e RIBEIRO, 2011, p. 240)

Na TPM, os operadores passam a executar tarefas mais simples de manutenção, como limpeza e lubrificação, uma vez que estes possuem maiores conhecimentos sobre os equipamentos que utilizam e podem, com isso, aumentar a confiabilidade destes, propiciando uma melhoria contínua (LIMA, SANTOS e SAMPAIO 2010). 


\section{Metodologia}

\subsection{Caracterização da pesquisa}

O procedimento aplicado a este estudo caracteriza-se como estudo de caso, embasado por uma revisão bibliográfica e entrevistas com os colaboradores, que proporcionaram um conhecimento aprofundado do contexto atual acerca do cenário das manutenções na instituição.

Dada a coleta de informações, utilizou-se da abordagem qualitativa, uma vez que foi baseada em informações coletadas subjetivamente, por meio da análise crítica dos autores e entrevistados, sem o uso de métodos numéricos e quantitativos.

Este estudo possui como propósito a aplicação de conhecimentos de modo a contribuir para a resolução de um problema particular através da implantação do plano proposto. Logo, a classificação quanto à natureza apresenta-se como aplicada (GIL, 2008; CERVO, BERVIAN, 2002).

Além disso, possui caráter exploratório, uma vez que foi feito o estudo de possíveis soluções para os problemas atuais da organização conjuntamente à proposição de medidas para a implantação de procedimentos do PCM.

\subsection{Coleta de dados}

O presente estudo foi realizado na Universidade Federal do Ceará - Campus Russas, com foco na aplicação dos conceitos de manutenção no sistema de refrigeração, mais precisamente, os aparelhos de ar-condicionado.

A princípio ocorreram entrevistas informais junto aos funcionários da prefeitura da unidade, onde os referidos relataram que atualmente não se possui uma equipe de manutenção dos seus equipamentos, onde os funcionários contratados para os demais setores realizam atividades paliativas como limpeza a cada três meses ou, em casos mais graves, ocorre a contratação externa.

Em virtude do ato de manutenção suceder a quebra ou falha do equipamento, ou seja, da atual estratégia de manutenção adotada ser a corretiva, a instituição declarou não reconhecer a necessidade da elaboração de um histórico de falhas, que pudessem embasar um plano de manutenção.

Diante disso, optou-se pela aplicação dos conceitos do PCM, dado o suporte nas atividades de manutenção e padronização dos processos para a criação de um histórico de falhas, bem como os reparos efetivados. 
Para a realização da proposta de implantação estabeleceu-se como modelo a ser seguido o proposto por Viana (2002), adaptando conceitos e metodologias ao cenário da instituição. O estudo foi finalizado com a proposição de melhorias, relato das dificuldades e benefícios esperados.

\section{Proposta de Implantação do PCM}

\subsection{Tagueamento}

Inicialmente realizou-se a proposição do tagueamento dos itens para facilitar a identificação. Para isso, foi formulada uma regra de padronização das tags (Figura 5).

Figura 5 - Regra para a padronização das tags

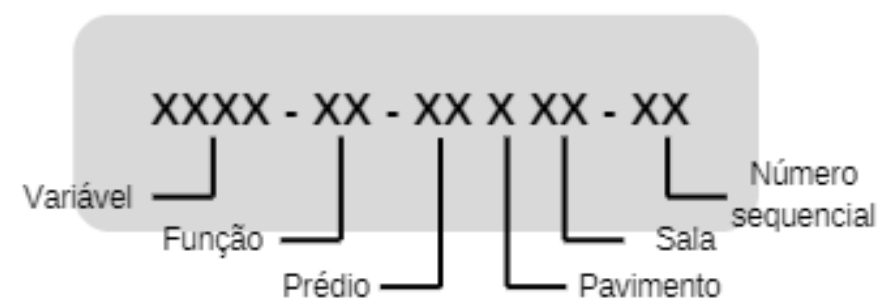

Fonte: Autores (2019)

Baseado neste modelo, foi proposto a aplicação da tag em um equipamento da instituição (Figura 6), o aparelho que possui como função principal a refrigeração do ambiente, localizado no primeiro prédio listado na planta do Campus, no segundo pavimento e presente na sala 01 , situado mais próximo da entrada do cômodo.

Figura 6 - Exemplo da aplicação da tag

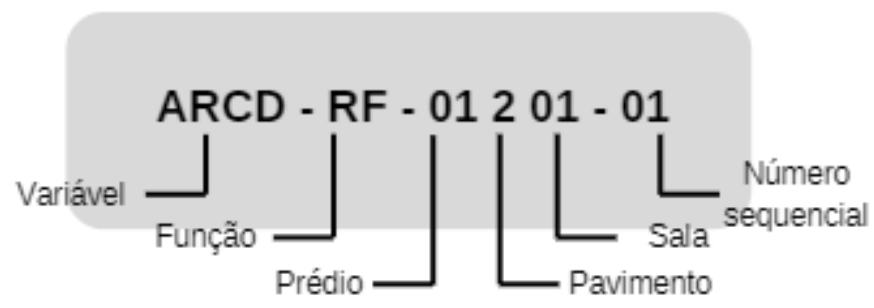

Fonte: Autores (2019)

\subsection{Ordens de serviço}

Posteriormente, elaborou-se uma OS, visto a necessidade de controle das manutenções realizadas. Dentre as informações apresentadas, encontra-se o tipo de manutenção executada, suas datas e atividades realizadas. O modelo apresentado na Figura 7 descreve os dados necessários para aprová-las ou não. 


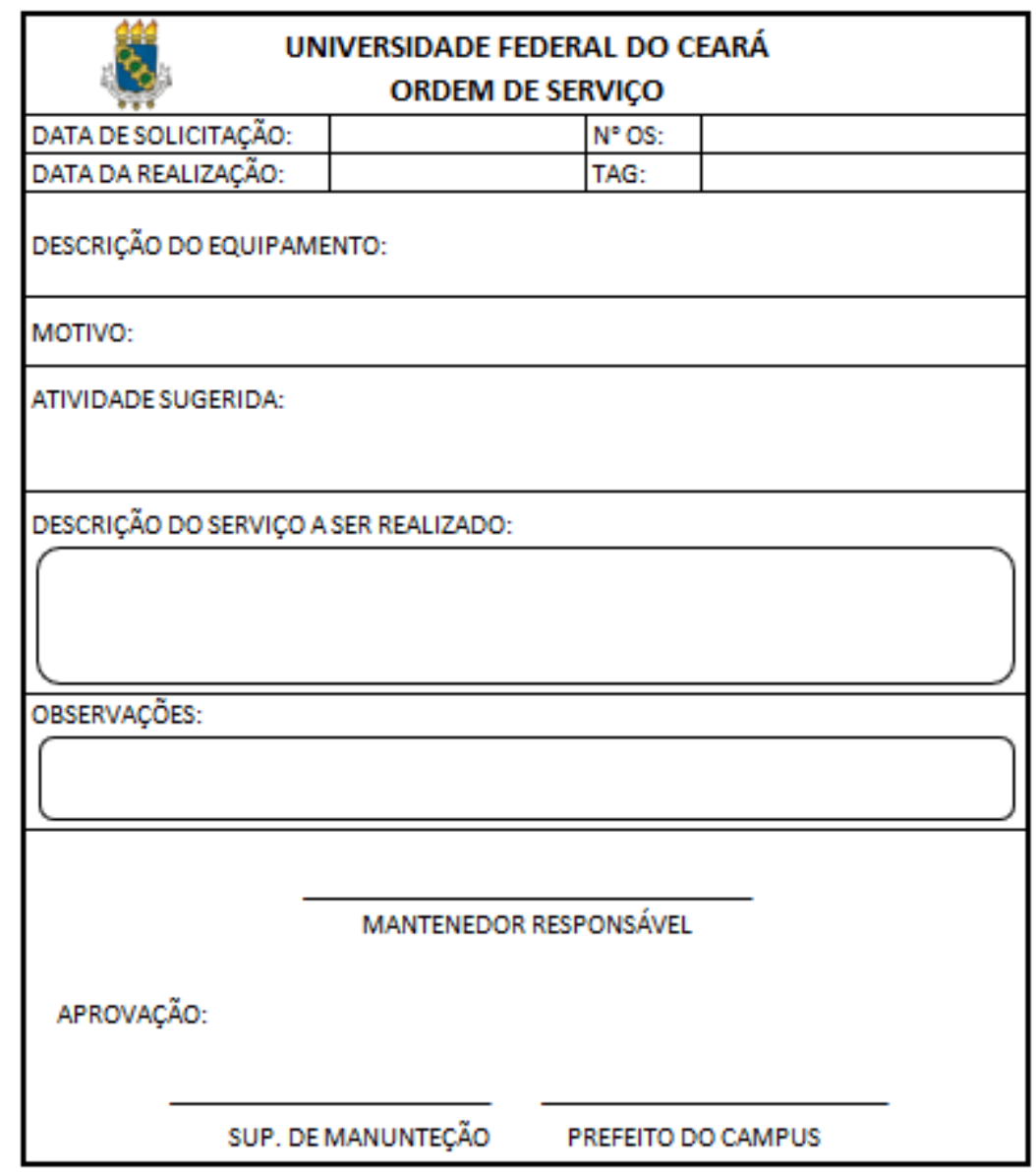

Fonte: Autores (2019)

\subsection{Cadastros}

Durante a realização das solicitações da OS, bem como das manutenções, se faz necessário conhecer o equipamento em que as atividades serão realizadas. Deste modo, sugere-se a elaboração de um documento para realizar o cadastro dos diversos modelos de ar-condicionado existentes.

O documento deve conter informações como: local onde estão situados, suas quantidades, principais características técnicas e fotos para facilitar a sua distinção, conforme a Figura 8. 
Figura 8 - Modelo de documento para cadastro de equipamentos

UNTVERSIDADE FEDERAL DO CEARÁ - CAMPUS RUSSAS

CADASTRO DE EQUIPAMENTOS - SISTEMA DE AR CONDICIONADO

\begin{tabular}{|c|l|}
\hline MODELO: & \\
\hline QUANTIDADE & \\
EXISTENTE NO CAMPUS: & \\
\hline SALAS QUE POSSUEM & \\
ESTE MODELO: & \\
\hline
\end{tabular}

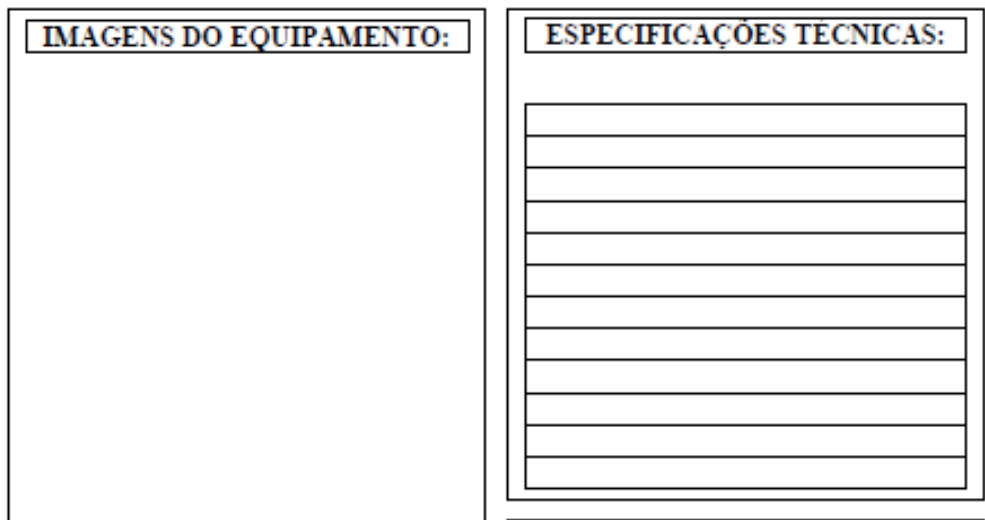

RECOMENDAĆOES DO FABRICANTE:

(PARA MAIORES INFORMAÇOES, CONSULTE O MANUAL ANEXADO A ESTE DOCUMENTO) OBSERVAÇÕES:

Fonte: Autores (2019)

\subsection{Análise de criticidade}

Para a realização dessa atividade, primeiramente deve ocorrer a segregação dos aparelhos de acordo com o nível de criticidade, por meio de uma avaliação qualitativa mediante critérios previamente estabelecidos baseado no método $\mathrm{ABC}$. Os critérios que irão distinguir os equipamentos em tais níveis estão especificados no Quadro 3. 
Quadro 3 - Análise de criticidade dos equipamentos

\begin{tabular}{|c|c|c|c|}
\hline & ALTA (A) & MÉDLA (B) & BAIXA (C) \\
\hline Taxa de Ocupação (TO) & $\begin{array}{l}\text { A sala é ocupada em sua integridade } \\
\text { durante os turnos de funcionamento }\end{array}$ & $\begin{array}{c}\text { Em alguns horários a sala é ocupada } \\
\text { em sua integridade, porém em } \\
\text { outros momentos a ocupação é } \\
\text { reduzida }\end{array}$ & $\begin{array}{c}\text { Em todos os horários de } \\
\text { funcionamento da sala, a mesma não } \\
\text { é ocupada em sua integridade }\end{array}$ \\
\hline Eficiência do Aparelho (EA) & $\begin{array}{l}\text { O aparelho possui uma boa } \\
\text { eficiência, consumindo menos } \\
\text { energia }\end{array}$ & $\begin{array}{c}\text { O aparelho possui eficiência } \\
\text { intermediária, consumindo mais } \\
\text { energia do que o necessário }\end{array}$ & $\begin{array}{c}\text { O aparelho possui baixa eficiência e } \\
\text { produz um maior consumo de } \\
\text { energia }\end{array}$ \\
\hline Frequencia do Uso (FU) & A sala é utilizada por 3 turnos & A sala é utilizada por 2 turnos & A sala é utilizada por 1 turno \\
\hline $\begin{array}{c}\text { Quantidade de Aparelhos no } \\
\text { Ambiente (QA) }\end{array}$ & $\begin{array}{l}\text { Todos os aparelhos do ambiente } \\
\text { estão funcionando como o esperado }\end{array}$ & $\begin{array}{c}\text { Uma parte dos aparelhos está } \\
\text { funcionando devidamente, no } \\
\text { entanto outros estão apresentando } \\
\text { falha }\end{array}$ & $\begin{array}{l}\text { Todos os aparelhos do ambiente } \\
\text { estão apresentando algum tipo de } \\
\text { falha, necessitando de manuenção }\end{array}$ \\
\hline
\end{tabular}

Fonte: Adaptado de Dynamox (2019)

\subsection{Classificação dos ativos em termo de criticidade}

Nesta fase, deve-se utilizar o fluxograma decisional (Figura 9) elaborado para definir qual tipo de manutenção ocorrerá no equipamento analisado em conjunto com o quadro da análise de criticidade.

Figura 9 - Fluxograma decisional

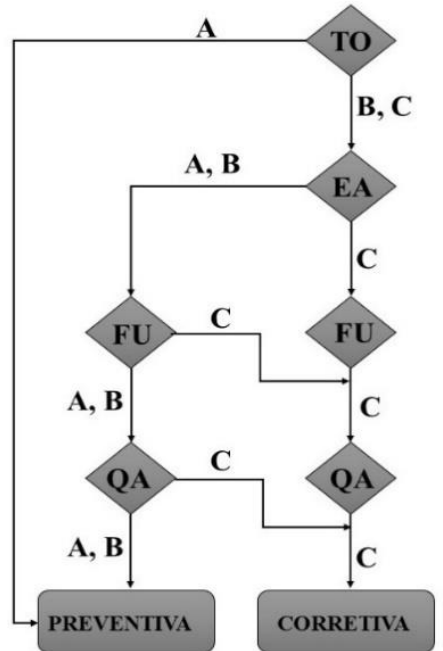

Fonte: Adaptado Dynamox (2019)

\subsection{Registro de histórico}

A instituição não possui registro de histórico de falhas, o que resulta em uma carência de informações sobre período passados. Portanto, para um maior controle das irregularidades no funcionamento dos ar-condicionados, elaborou-se um modelo para o registro do histórico de falhas. Este registro deve ser feito para cada equipamento, onde o manutentor precisará explicitar todas as informações solicitadas, como mostrado na Figura 10. 
Figura 10 - Modelo para o registro do histórico de falhas

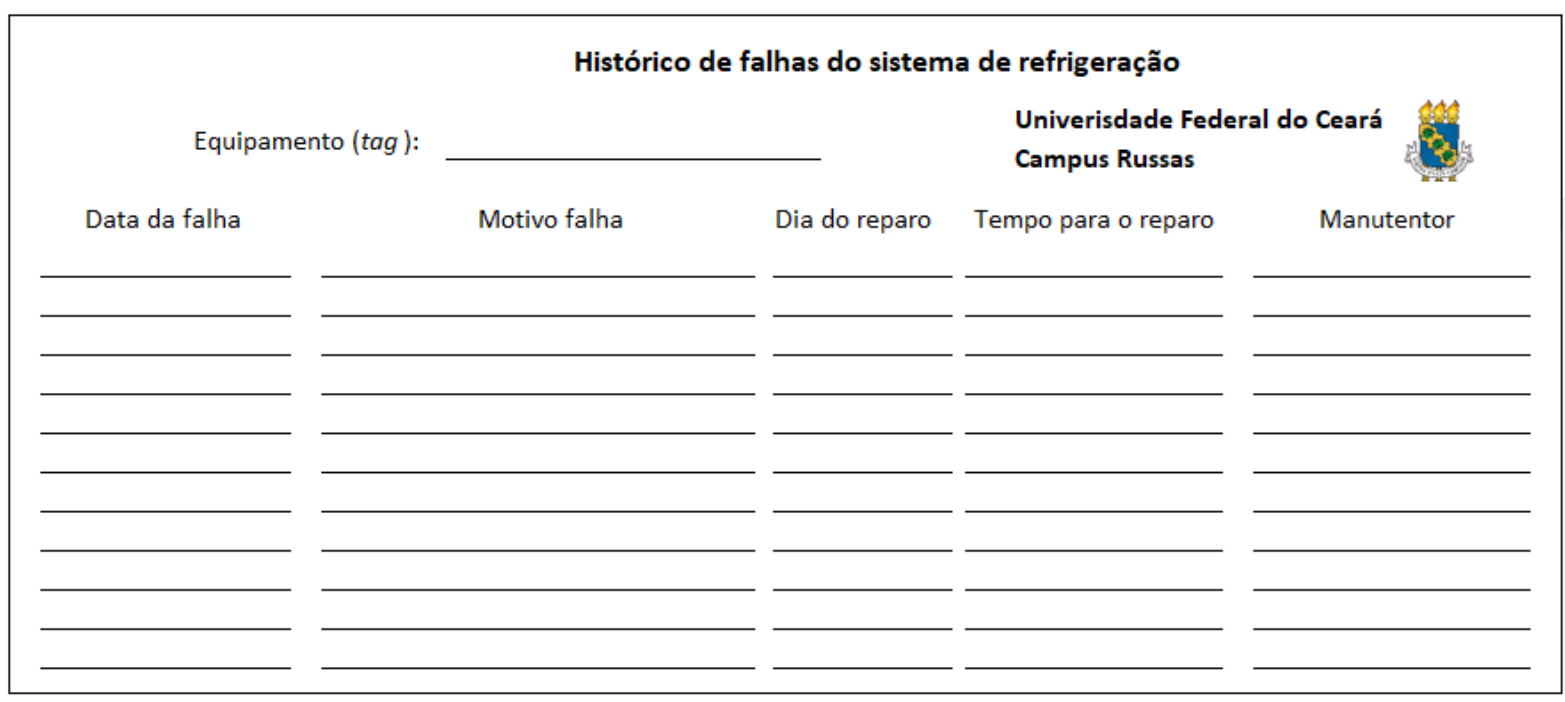

Fonte: Autores (2019)

\subsection{Equipes de manutenção}

Atualmente a empresa contrata terceiros para a realização das atividades de manutenção corretiva. Todavia, tendo em vista a quantidade de colaboradores disponíveis na instituição que podem exercer a função de manutentor, sugere-se a seleção e capacitação dos funcionários para realizar tais atividades, onde eles devem efetuar a manutenção autônoma, que pode resultar na redução dos custos direcionados a estas operações. Para pôr em prática tal sugestão, elaborouse um plano de ação para capacitação das equipes selecionadas, conforme a Figura 11. 
Figura 11 - Plano de ação para capacitação das equipes de manutenção

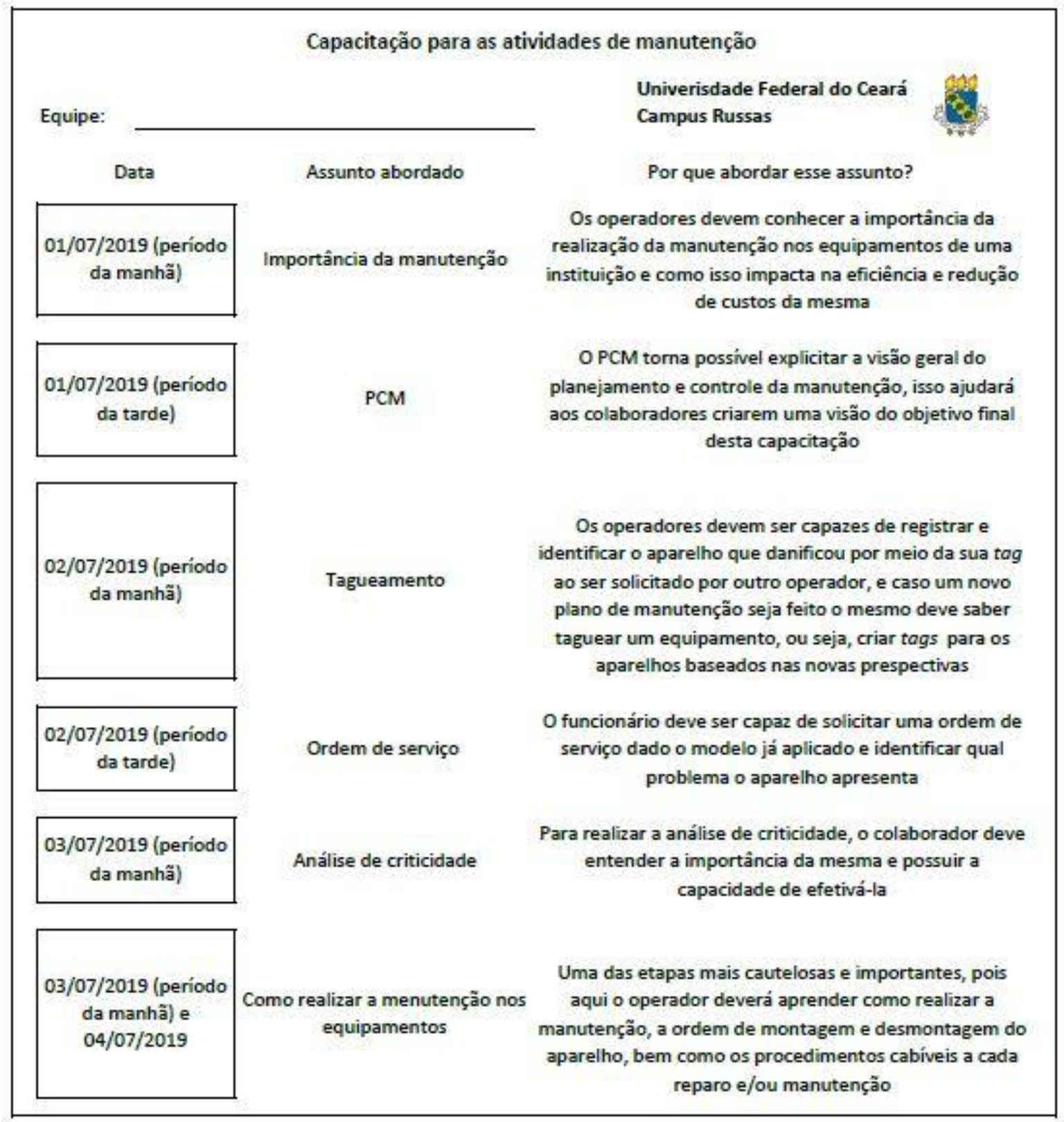

Fonte: Autores (2019)

\subsection{Plano de manutenção}

O plano recomendado deve ser constituído pelos dados coletados anteriormente e apresentar informações relevantes como a descrição do equipamento, o intervalo de tempo entre as manutenções, os insumos necessários para efetuar as atividades e os procedimentos realizados. O modelo elaborado pelos pesquisadores foi baseado nas informações descritas como essenciais por Viana (2002) e está descrito na Figura 12: 
Figura 12 - Modelo de plano de manutenção preventiva

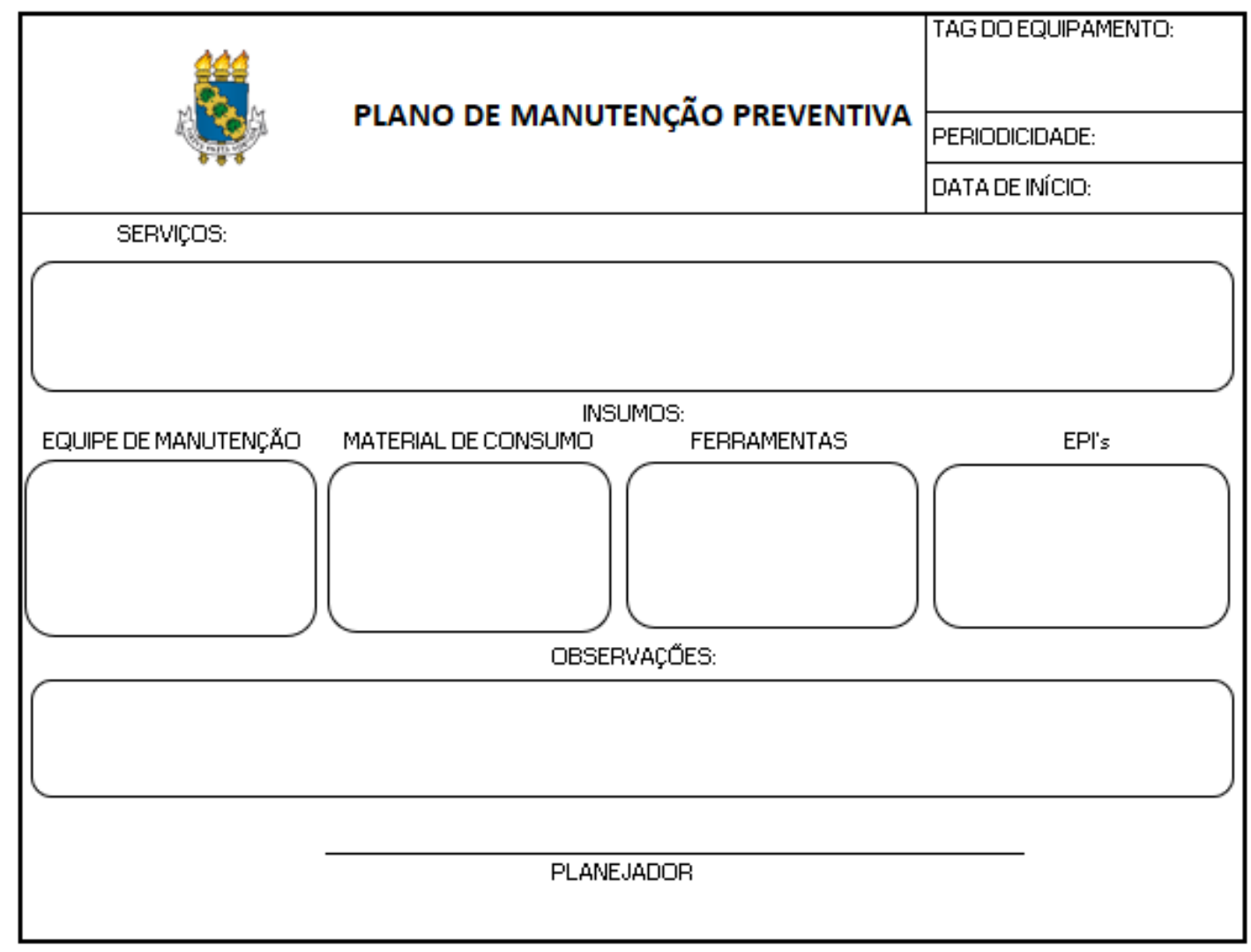

Fonte: Autores (2019)

\subsection{Indicadores}

Dada a proposta do plano de manutenção e a elaboração de um histórico, surge a necessidade da criação de indicadores para medir a efetividade do projeto após a sua implantação. Os indicadores propostos para viabilizar a avaliação de desempenho da universidade e suas definições são mostrados na Figura 13.

Figura 13 - Indicadores

\begin{tabular}{|c|c|}
\hline INDICADOR & DEFINIÇÃO \\
\hline $\begin{array}{c}\text { Índice de gastos com } \\
\text { quebra de aparelhos }\end{array}$ & $\begin{array}{c}\text { Cálculo de todos os gastos obtidos } \\
\text { com quebra dos aparelhos }\end{array}$ \\
\hline Ocorrência de problemas & $\begin{array}{c}\text { Quantidade de problemas que } \\
\text { ocorreram mesmo após implantação } \\
\text { de manutenções preventivas }\end{array}$ \\
\hline Indisponibilidade & $\begin{array}{c}\text { Calculado através do tempo médio } \\
\text { que os equipamentos ficam parados, } \\
\text { sem funcionar, esperando reparo }\end{array}$ \\
\hline Tempo médio entre falhas & $\begin{array}{c}\text { Avaliado através do cálculo das } \\
\text { médias do tempo que um } \\
\text { equipamento leva para falhar }\end{array}$ \\
\hline Tempo médio para reparo & $\begin{array}{c}\text { Medido por meio da média do tempo } \\
\text { para a realização de um reparo do } \\
\text { equipamento }\end{array}$ \\
\hline
\end{tabular}

Fonte: Autores (2019) 
A análise de tais indicadores deve ser feita em comparativo com períodos anteriores, pois se forem ineficientes diante dos dados passados, é conveniente que uma nova estratégia de manutenção seja elaborada.

\section{Análise e discussão dos resultados}

O estudo de caso aplicado neste trabalho propôs a implantação do PCM, baseado na estruturação e organização das suas principais atividades para alcançar o melhor funcionamento do sistema de refrigeração analisado.

O tagueamento facilitará a localização dos equipamentos, portanto, sugere-se acrescentar as etiquetas em cada ar-condicionado do Campus nas plantas baixas. Além disso, se faz necessário adicionar esta etiqueta a cada aparelho, em um local padrão que permita uma fácil identificação e auxílio aos colaboradores. Foi proposto também um documento para realizar o cadastro e arquivamento dos modelos de ar-condicionado, o qual deve ser armazenado na sala da prefeitura do Campus, anexado ao manual de instruções para cada modelo existente.

Com o intuito de obter um requerimento de manutenção padronizado, espera-se também o estabelecimento efetivo das OS após a aprovação da referida, onde a etapa seguinte é a programação da manutenção sugerida, devendo esta ser executada e adicionada ao histórico de manutenções.

Outro ponto abordado foi a necessidade de realização da análise de criticidade dos equipamentos de ar-condicionado, a qual exprime o impacto que o ativo possui dentro do sistema. De acordo com os parâmetros listados na análise de criticidade é possível realizar a escolha do ato de manutenção que proporcione o aumento na confiabilidade dos equipamentos. Por se tratar de uma universidade pública que depende de investimentos do governo e de licitações para que ocorram atividades em sua infraestrutura, definiu-se que as manutenções mais viáveis para sua realidade seriam a preventiva ou a corretiva, visto que a manutenção preditiva requer um maior acompanhamento, necessitando de recursos financeiros, além de insumos como mão-de-obra e equipamentos que provavelmente não estariam disponíveis no Campus.

Outra recomendação diz respeito ao registro de um histórico de manutenções, visto que este é fundamental para o gerenciamento e tomada de decisões. Segundo Viana (2002), um banco de dados organizado é uma poderosa arma de pesquisa que fornece referências para escolhas a 
respeito de projeto de engenharia, análise de fornecedores de sobressalentes, melhoria da mantenabilidade e mensuração de indicadores para tomada de decisão.

Sobre as equipes de manutenção, foi considerada a possibilidade de se trabalhar com a manutenção autônoma, na qual o operador torna-se capaz de realizar a lubrificação, limpeza e desempenhar os procedimentos com o máximo de cuidado necessário. Espera-se, com isso, uma redução dos índices de quebras dos equipamentos.

Devido à importância da padronização e a necessidade de um escopo a ser seguido, bem como a utilização de forma correta das informações coletadas, espera-se que o modelo do plano de manutenção proposto neste estudo seja instaurado e seguido por todos os colaboradores da instituição, assim, através dos indicadores sugeridos, o gestor do Campus será capaz de avaliar a eficiência do plano de manutenção e seu impacto nos custos com quebra de equipamentos.

\section{Conclusão}

O objetivo deste artigo foi a elaboração de um modelo de PCM para uma instituição de ensino, com intuito de garantir uma maior eficiência na manutenção dos equipamentos. As limitações desta pesquisa podem ser explicitadas em: inexistência de um histórico de dados que permitisse a realização de um estudo quantitativo e dificuldade de localizar materiais relacionados ao assunto.

Os resultados voltaram-se à elaboração de modelos para o tagueamento, padronização das OS, cadastros dos equipamentos já existentes na instituição e classificação dos ativos em termos da criticidade para fomentar o auxílio às equipes de manutenção. Criou-se ainda propostas para o registro de histórico e o plano de manutenção, bem como um plano de ação contendo as etapas e datas para um possível treinamento das equipes, tornando os colaboradores aptos às atividades manutentoras. Por fim, definiu-se indicadores capazes de avaliar o desempenho do plano proposto.

Diante disso, é factível afirmar que o objetivo proposto inicialmente foi alcançado, pois o plano de manutenção elaborado se adaptada à realidade da universidade estudada. O PCM permitirá um maior controle sobre a vida útil dos equipamentos, redução do número de defeitos e quebras, bem como dos custos com paradas e manutenções.

Para trabalhos futuros sugere-se a implantação e realização da análise de eficiência do plano proposto, quantitativamente, por meio do acompanhamento das manutenções e troca de peças durante um período determinado. Este período deve ser definido de modo que permita verificar 
se houve a ocorrência de uma menor taxa de quebra, menos gastos com manutenção e mais estabilidade na vida dos equipamentos.

\section{REFERÊNCIAS}

ASSOCIAÇÃO BRASILEIRA DE NORMAS TÉCNICAS. Confiabilidade e mantenabilidade. Rio de Janeiro, 1994.

CERVO, Amado Luiz; BERVIAN, Pedro Alcino. Metodologia Científica. 3. ed. São Paulo: McGraw-Hill, 2002.

COSTA, Mariana de Almeida. Gestão estratégica de manutenção: uma oportunidade para melhorar o resultado operacional. Trabalho de conclusão de curso (Graduação em Engenharia de Produção) - Universidade Federal de Juiz de Fora, 2013.

CARVALHO, André Moreira de; GOMES, Geraldo Messias; BORGES, Márcio de Castro; FERREIRA JÚNIOR, Nilton Bráz. Implantação de sistema informatizado para Planejamento e Controle da Manutenção - Empresa Vileflex. Universidade Vale do Rio Doce (UNIVALE) e Faculdade de Ciências Exatas e Tecnológicas (FAENG). Governador Valadares, MG, 2009.

DCI. Indústria de ar-condicionado espera crescer com demanda residencial. Disponível em: $<$ https://www.dci.com.br/industria/industria-de-ar-condicionado-espera-crescer-com-demanda-residencial1.701236>. Acesso em: 26 de jun. 2019.

DYANMOX. Criticidade de equipamentos na indústria: como definir prioridades na manutenção. Disponível em: <https://dynamox.net/criticidade-de-equipamentos-na-industria/>. Acesso em: 20 de Jun. 2019.

FOGLIATTO, Flávio Sanson.; RIBEIRO, José Luis Duarte. Confiabilidade e manutenção industrial. Rio de Janeiro: Elsevier: ABEPRO, 2011.

GIL, Antônio Carlos. Métodos e técnicas de pesquisa social. 6 ed. São Paulo: Atlas, 2008.

HÜNEMEYER, Felipe Jacó. Proposta de implantação das funções de Planejamento e Controle da Manutenção (pcm) em uma linha de produção. Centro Universitário Univates. Curso de Engenharia de Produção. Lajeado, 2017.

KARDEC, Alan; NASEIF, Júlio. Manutenção: função estratégica. $3^{\text {a }}$ edição. Rio de Janeiro: Quaitymark: Petrobrás, 2009.

LIMA, José Ricardo Tavares de; SANTOS, Alex Alisson Bandeira; SAMPAIO, Renelson Ribeiro. Sistemas de gestão da manutenção - uma revisão bibliográfica visando estabelecer critérios para avaliação de maturidade. XXX Encontro Nacional de Engenharia de Produção. São Carlos, SP, 2010.

KIGSIRISINA, Soraphon; PUSSAWIROA, Sirawit; ONURAI, Noohawmb. Approach for Total Productive Maintenance Evaluation in Water Productivity: A Case Study at Mahasawat Water Treatment Plant. 
Procedia Engineering vol. 154, 2016 p. 260 - 267.

SINGH, Ranteshwar; GOHIL, Ashish M; SHAH, Dhaval B; DESAI, Sanjay. Total Productive Maintenance (TPM) Implementation in a Machine Shop: A Case Study. Procedia Engineering vol. 51, 2013 p. 592 - 599.

SOUZA, José Barrozo. Alinhamento das estratégias do Planejamento e Controle da Manutenção (PCM) com as finalidades e função do Planejamento e Controle da Produção (PCP): uma abordagem analítica. Dissertação (Mestrado em Engenharia de Produção) - Universidade Tecnológica Federal do Paraná, Campus Ponta Grossa, 2008.

VIANA, Herbert Ricardo Garcia. PCM, Planejamento e Controle da Manutenção. $1^{a}$ Edição. Rio de Janeiro: Qualitymark Editora. 2002. 